\title{
MicroRNAs AS BIOMARKERS FOR ACUTE MYOCARDIAL INFARCTION - SMALL MOLECULES WITH A HUGE POTENTIAL
}

\author{
Miskowiec Dawid, ${ }^{1}$ Kasprzak Jaroslaw D. ${ }^{1}$ \\ ${ }^{1}$ Department of Cardiology, Medical University of Lodz, Poland
}

Primljen/Received 01. 08. 2015. god.

Prihvaćen/Accepted 07. 08. 2015. god.

\begin{abstract}
MicroRNAs (miRNAs) are a conserved class of small, 17-25 nucleotides long, noncoding RNAs. They act as controllers of gene expression patterns, either by blocking translation or inducing miRNA degradation by sequence-specific hybridization. Several miRNAs have been proposed as potential disease-specific biomarker in cardiovascular diseases. The diagnostic value of assessing circulating miRNAs levels has been evaluated in numerous studies, mainly regarding acute myocardial infarction. Initial promising results from preclinical studies suggest the potential for future miRNA-based therapies. In our review, we focus on the current developments showing the role of miRNAs in the acute myocardial infarction, emphasizing diagnostic utility of miRNAs as promising new biomarkers of AMI and their therapeutic potential.

Key words: microRNA, myocardial infarction, coronary artery disease, myocardium, gene expression regulation.
\end{abstract}

\section{INTRODUCTION}

Sequencing the human genome has emerged as one of most futuristic research tools at the start of this millennium. Among many breakthrough data, researchers revealed that, surprisingly, only less than $2 \%$ of total human genomic DNA sequences contain protein-coding genes information $(1,2)$. Current evidence indicates that significant part of the remaining DNA sequences is involved in the production of noncoding RNAs. It is thought that up to $96 \%$ of the cell RNA is in fact non-coding RNA which is mostly engaged into regulatory processes modifying the information flow from DNA sequence to protein structure (2). MicroRNAs (MiRNAs) have been found to be one of the abundant classes of gene regulatory molecules (3), and therefore the old paradigm about proteins as main gene expression regulators has been overthrown. As a new pivotal element of human transcriptome regulation, and consequently important modulators of many physio- and pathophysiological processes, miRNAs are fueling new era of research in the field of cardiovascular diseases.

Among all cardiovascular diseases acute myocardial infarction (AMI) remains a leading cause of death worldwide. Despite the improvement of therapeutic approaches, AMI is still associated with severe long-term complications, such as development of chronic heart failure. Therefore, the development of new therapeutic approaches and deeper molecular understanding of pathological processes involved into acute myocardial ischaemic damage are crucial for both basic cardiovascular and clinical research.

\section{MiRNA - THE BIOGENESIS AND FUNCTION}

MiRNAs are small, evolutionary conserved small ribonucleic acid molecules (17-25 nucleotides in length) which have recently become the focus of intensive research effort among the different noncoding RNA variants $(3,4)$. They interact with specific, complementary coding mRNA targets and substantially contribute to post-translational mRNA regulation by either blocking translation or inducing degradation of the target mRNAs (5). Recent evidence indicates around 2000 miRNA types existent in humans (the current release of miRBase ver. 21 , available at the website www.miRBase.org contains 1,881 precursors and 2,588 mature human miRNAs), which are thought to regulate more than half of the protein-coding gens in humans (6). Genome-wide studies focused on the relationship between miRNAs, mRNAs and protein output have shown their regulatory function. The degradation process of miRNAs targets is a widespread phenomenon and accounts for most of the miRNA-mediated 
protein repression (66-90\%) observed in cultured cells (4, 7-9). Moreover, the vast part of these miRNAs is tissue-specific (10), what makes them even more attractive and at the same time challenging research target. Furthermore, miRNAs are secreted into the extracellular space and circulation (via exosomes or microvesicles), where are easily accessible to measure as potential biomarkers in a range of cardiovascular diseases (11-13).

The detailed miRNAs biogenesis has been discovered only recently. The majority of miRNAs genes are initially transcribed to long primary miRNA transcripts (pri-miRNA) by RNA polymerase II and RNA polymerase III. This precursor hairpin pri-miRNA are subsequently spliced by microprocessor complex which contains Drosha (ribonuclease III) $(14,15)$, and its size is reduced to 70-100 nucleotides in length - pre-miRNA. Then, pre-miRNA is exported from the nucleus to the cytoplasm by exportin-5 to be cleaved by $\mathrm{Di}$ cer-complex resulting in small, double-stranded miRNA duplex. Further interaction of Dicer-complex with other proteins leads to dissociation of the miRNA duplex into the functional strand (which is complementary to the target-mRNA) and the passenger strand (which is mainly subsequently degraded). The mature functional strand of miRNA is incorporated together with Argonaute-2 protein (AGO2) into the RNA-induced silencing complex (RISC), which performs gene silencing by either translation inhibition or promoting of target mRNA degradation $(3,5,15)$. Moreover, cytoplasmic pre-miRNA can be incorporated into small vesicles - exosomes, whose origin are endosomes, and then within exosomes can be released from cells by fusion with the plasma membrane. Another source of circulating miRNA (pre-miRNA or mature miRNA) are miRNA loaded microvesicles, which are released from the cytoplasme through the direct plasma membrane blebbing (16). Moreover, miRNAs can also be present in circulation in its vesicle-free form, as combined with high-density lipoproteins (HDL) or bound to RNA-binding proteins (such as AGO2) (16).

\section{MiRNAs AS BIOMARKERS OF AMI}

Up to date, creatine kinase-MB (CK-MB) and cardiac troponins (cTn) are still the most frequently used biomarkers for AMI, however, their clinical utility in many cases remains limited. In the past few years, the important role of circulating miRNAs in the cardiovascular system has been widely investigated. The importance of miRNAs as intercellular messengers has risen with proposed potential use as circulating biomarkers $(12,16,18)$ after they were detected in various body fluids (serum, plasma, saliva, tears and urine) (17). Re- cently, it was also discovered that miRNAs circulating in the bloodstream are resistant to RNAse degradation and remain remarkably stable in stored samples, boiling water, in solution with very high or low pH (16, 19). Moreover, plasma miRNAs remain highly stable when subjected to prolonged room temperature storage or even multiple freeze-thaw cycles (20). The extraordinary stability of miRNAs in circulating blood is due to the fact that circulating miRNAs are mainly incorporated into exosomes, microvesicles, and apoptotic bodies as well as they form stable complexes with RNA-binding proteins and HDL lipoprotein (11, 13, 19). After miRNA biomarkers were indicated as potential biomarkers for cardiovascular diseases, enormous efforts have been made to improve the detection technologies and quantification has become readily accessible (21-23). Therefore, the accurate, rapid, convenient and inexpensive analytic instruments to detect miRNA may be used in clinical practice in the near future. To date, the role of miRNAs as biomarkers has been documented for many different cardiovascular diseases, such as heart failure, cardiac hypertrophy, hypertension, atherosclerosis and myocardial infarction $(12,24,25)$. Some specific circulating cardiac-enriched or cardiac-specific miRNAs (miRNA-208, miRNA-499, miRNA-133) may provide additive diagnostic value as biomarkers for AMI diagnosis (26).

\section{miRNA-208}

MiRNA-208 is a highly cardiac-specific miRNA (18). This intronic miRNA is coexpressed with myosin genes (27). There are two subtypes of miRNA 208 (miRNA 208a and miRNA-208b) and both have been shown to be upregulated in AMI, however the miRNA-208b studies have been described more frequently in humans (28). MiRNA-208 appears in the bloodstream relatively fast after the AMI onset (29) and become detectable within 1-4 h of symptoms onset, when cardiac troponins are still below the cut-off value $(30,31)$. The proposed explanation for this phenomenon is the fact that cardiac troponins are mainly bound to myofibrils and only small part of them is cytosolic, whereas miRNAs as bound to protein complex are predominantly cytosolic $(25,30)$. Zile et al. investigated temporal changes in specific miRNAs and concluded that miRNA-208a was still significantly elevated 5 days after AMI and remained upregulated up to 90 days after AMI (32). The superiority of miRNA-208 to cardiac troponin I (cTnI) in early diagnosis of AMI has been also shown by Wang et al. In their study evaluating set of miRNAs (miRNA-1, miRNA-133a, miRNA-208a and miRNA-499) elevated levels of miRNA-208 were observed in all of patients within $4 \mathrm{~h}$ of the onset of 
AMI symptoms contrary to cardiac troponin I (cTnI) which was elevated only in $85 \%$ of AMI patients (30). In receiver operating characteristic curve (ROC) analysis miRNA-208a revealed the highest specificity (100\%) and sensitivity (90.9\%) for distinguishing AMI from other cardiovascular disorders (30). Noteworthy, miRNA-208a is undetectable in plasma from patients free of cardiovascular disease, but including patients with trauma, chronic renal failure, stroke and acute kidney injury (30). Similar results were presented for miRNA-208b by Corsten et al. (33), who demonstrated that miRNA-208a expression helped discriminate between patients with ST segment elevation AMI (STEMI) and non-ST elevation AMI (NSTEMI) patients (34). Li et al. investigated the altered profile of serum miRNAs in AMI patients at a relative early stage. They identified a profile of six serum miRNAs (miRNA-1, miRNA-134, miRNA-186, miRNA-208, miRNA-223, miRNA-499) as AMI biomarkers, and miRNA-208 and miRNA-499 in their study were surprisingly overexpressed in angina pectoris patients in comparison to AMI cases (35). In other study on relatively large cohort of 424 patients with suspected acute coronary syndrome, miRNA-208b discrimination of patients diagnosed with AMI from non-AMI was accurate $(\mathrm{AUC}=0.82)$, but significantly lower than for cardiac troponi $\mathrm{T}(\mathrm{cTnT})(\mathrm{AUC}=0.95)(36)$. Although the increased level of miRNA-208b was also strongly associated with early mortality and heart failure within 30 -day $(\mathrm{OR}=1.8 ; 95 \% \mathrm{CI}: 1.4-2.2)$, this association was lost after adjustment for cTnT (36). Similar findings were observed in a prospective, international multicenter, blinded study by Devaux et al. on 1155 subjects presenting witch acute chest pain to the emergency department. The authors investigated the diagnostic value of six circulating miRNs (miRNA-133a, miRNA-208b, miRNA-223, miRNA-320a, miRNA-451 and miRNA-499) and have found significantly higher levels of miRNA-208b, miRNA-499 and miRNA-320 in AMI patients. From all studied miRNAs, miRNA-208b provided the highest diagnostic accuracy for AMI (AUC $\mathrm{AmiRN}_{\text {-208b }}=0.76 ; 95 \% \mathrm{CI}$ : $0.72-0.80)$, but was lower than cTnT $\left(\mathrm{AUC}_{\mathrm{cTnT}}=0.84\right)$ or high sensitivity cardiac troponin $\mathrm{T}$ (hs-cTnT) $\left(\mathrm{AUC}_{\mathrm{hs}-\mathrm{CTnT}}=0.94\right)$. Furthermore, miRNA-208b levels were higher in patients who died within 30 days, but its prognostic value for predicting long-term mortality has been lost (37). The explanation of lower accuracy of miRNA-208b lies in the fact that miRNA-208b, contrarily to miRNA-208a, is not cardiac-specific with high expression in skeletal muscle $(27,38)$. Particularly interesting from the clinical point of view are results from a study by Widera et al., who assessed diagnostic value of six circulating miRNAs in 444 subjects with acute coronary syndrome (miRNA-1, miRNA-133a, miRNA-208a/b and miRNA-499). In this study, subjects with myocardial infarction presented with significantly higher levels of miRNA-208b, miRNA-133a and miRNA-1 (39). Recently, in meta-analysis Cheng et al. summarized and analyzed the role of circulating miRNAs (miRNA-1, miRNA-133a, miRNA-208a, miRNA-499) in the diagnosis of AMI. They estimated an overall sensitivity of $78 \%$, specificity of $82 \%$, and $\mathrm{AUC}=0.91$ for overall miRNA discrimination of MI. In summary, they have also shown that miRNA-208b had the quite high sensitivity $(78 \%$; 95\%CI: $76-81 \%)$ and the highest specificity (88\%; 95\%CI: $84-91 \%$ ) from all cardiac miRNAs included into the study. The authors found strong correlations between studied miRNAs and other classic biomarkers of AMI such as cTnT, hs-cTnT, CK and CK-MB (40).

\section{miRNA-499}

MiRNA-499 belongs to a family of microRNAs encoded by myosin genes, and is specifically encoded by an intron of the Myh7b, a ventricular-specific myosin heavy chain gene (27). MiRNA-499 is almost selectively expressed in the heart tissue and has been found elevated in acute ischaemic heart injury $(30,41)$. Detailed kinetics of plasma miRNA-499 expression in clinical settings presented Chen et al. in the study on 73 patients with acute coronary syndrome. The measurable increase in miRNA-499 levels was observed in all AMI patients within 24h from the last onset of symptoms and returned to baseline after 7 days (40). Plasma miRNA-499 were already detectable as early as 1 hour after the chest pain onset in AMI subjects, and continued to rise gradually within 9 hours after onset of symptoms (42). In other study of AMI patients with chest pain onset $<3 \mathrm{~h}$, miRNA- 499 was detectable in $93 \%$ when hs-cTnT was positive only in $88 \%$, suggesting that miRNA-499 can be a novel and sensitive biomarker for AMI (34). However, the ROC analysis in the study by Li et al. showed no advantage for circulating miRNA-499 over cTnT in diagnosis of AMI (35). Interestingly, miRNA-499 levels in patients diagnosed with STEMI was significantly higher than in NSTEMI subjects, and only in STEMI group was negatively correlated with the ejection fraction (34). In another important large study, Devaux at al. investigated the role of cardiac miRNAs miRNA-208b and miRNA-499 in well-defined population of patients with STEMI $(\mathrm{n}=$ 397), NSTEMI ( $n=113)$, and healthy controls $(n=87)$. The authors reported highly elevated levels of both miRNAs ( $>10^{5}$ fold increase) in STEMI and NSTEMI and their nearly undetectable levels in healthy patients. Additionally, their levels correlated with peak concen- 
tration of traditional biomarkers (CK and hs-cTnT) and overall, miRNA-499 and hs-cTnT provided comparable diagnostic value with $\mathrm{AUC}=0.97$. However, combining studied miRNAs did not improve the diagnostic value of single biomarkers (34). Olivieri et al., demonstrated in elderly patients with NSTEMI that miRNA-499-5p (a miRNA-499 family member) levels increasenearly 80 -fold in geriatric NSTEMI patients compared with healthy controls. In their study diagnostic accuracy of miRNA-499-5p in differentiating NSTEMI from acute heart failure with modest cTnT elevation at presentation was superior to conventional (cTnT) and high sensitivity cardiac troponin $\mathrm{T}$ (hs-cTnT) $\left(\mathrm{AUC}_{\text {miRNA-499-5p }}=0.85\right.$ vs. $\mathrm{AUC}_{\mathrm{cTnT}}=0.68$ vs. $\left.\mathrm{AUC}_{\mathrm{hs}-\mathrm{CTnT}}=0.70\right)(43)$. Other recent study also demonstrated that miRNA-499-5p was significantly higher in AMI patients and was correlated with decreased systolic function, suggesting that miRNA-499-5p may potentially be used for the risk stratification (36).

In their previously mentioned meta-analysis Cheng et al. indicated that from all studied miRNAs (miRNA-1, miRNA-133a, miRNA-208a, miRNA-499) - miRNA-499 is most significantly associated with myocardial infarction, and has the highest sensitivity (88\%; 95\%CI: $86-90 \%)$ and specificity $(87 \%$; 95\%CI: $84-90 \%$ ) for AMI diagnosis (40).

Another clinically important results were presented by Yao et al. They evaluated early prediction of perioperative myocardial infarction in patients undergoing coronary artery bypass grafting (CABG) using miRNAs (44). The levels of miRNA-133a, miRNA-133b and miRNA-499 levels were assessed in CABG patients preoperatively, and 1, 3, 6, 12, 24 and 48 after aorta declamping). Interestingly, observed postoperative miRNAs peak was earlier (1-3 hours) than cTnI levels peak (at 6 hours after declamping) and peak plasma levels of miRNAs correlated significantly with cTnI (the strongest correlation was observed for miRNA-499, $r=0.58, p=0.001)$. In prospective selected cohort of 120 CABG patients miRNA-499 measured $6 \mathrm{~h}$ after surgery revealed the highest sensitivity (85.7\%), specificity $(93.3 \%)$ and AUC value (0.94; 95\% CI: $0.88-0.98$ ) for perioperative myocardial infarction prediction. It is also worth of underling, that cTnI has relatively poor predictive value for identification of perioperative AMI (sensitivity $64.3 \%$; specificity $86.5 \%$; $\mathrm{AUC}=0.79,95 \% \mathrm{CI}: 0.70-0.86)(44)$.

\section{miRNA 133}

MiRNA-133 is widely expressed in skeletal, cardiac, and smooth muscle cells of cardiovascular system (45). It has been proven that miRNA-133a regulates cardiomyocyte proliferation. In mice model genetic deletion of both miRNA 133a gens (miRNA-133a-1 and miRNA-133a-2) resulted in lethal ventricular septal defect in embryos or neonates, and dilated cardiomyopathy and heart failure in adult survivals (46).

In experimental rat model of AMI, circulating levels of miRNA-133a were increased at 1-3 h, peaked at 3-12h, and decreased at 12-24h after AMI induced by coronary artery ligation (30). In the study of 33 patients with AMI, plasma miRNA-133 levels increased 4.4 fold in comparison to controls (30). The ROC curves analysis revealed high accuracy of miRNA-133a in detecting individuals with $\mathrm{AMI}$ ( $\mathrm{AUC}=0.87 ; 95 \% \mathrm{CI}$ : 0.77-0.96). Moreover, the miRNA-133a plasma levels strongly correlated with cTnI and were substantially increased compared with healthy controls, the authors suggested that miRNA-133a as a potential biomarker may be particularly useful in early settings of AMI (30). Similar findings were reported by D'Allesandra et al., who observed earlier peak of miRNA-133a and miRNA-133b (156 $\pm 72 \mathrm{~min})$ after the onset of AMI symptoms than the conventional biomarkers such as cTnI (18). However, there is some discrepancy in reports on miRNA-133 in the AMI settings. In the study by Ai et al., no significant difference in plasma levels of miRNA-133 had been found between AMI and non-AMI patients (47).

\section{miRNA-1}

MiRNA-1 is another well-known muscle-specific miRNA. It is expressed mainly in cardiomyocytes and skeletal muscles with low expression in other human tissues. MiRNA-1 plays pivotal roles in development and differentiation of muscles tissues, especially the heart tissue (48). It is encoded by two genes: MIR-1-1 and MIR-1-2 located in two distinct chromosomes 18 and 20. Genetic deletion of MIR-1 gene (MIR-1-2) in mice model resulted in late embryonic lethality and sudden cardiac death in survivors, mainly due to arrhythmias $(49,50)$. It was proven that miRNA-1 may modulate cardiac arrythmogenic potential by targeting the gap junction protein - connexin (GJA1), and potassium ion channel $(\mathrm{KCNj} 2)(50)$.

Studies have shown that miRNA-1 expression is increased in both animal models and patients with AMI. The significantly higher levels of miRNA-1 in AMI patients plasma at hospital admission have been found in the study by Ai et al., with the area under ROC curve $\mathrm{AUC}=0.77$ (95\% CI: $0.71-0.84)$ for distinguishing between AMI and non-AMI subjects. They have also proven that miRNA-1 levels was not associated with age, gender and other comorbidities, such as diabetes mellitus or hypertension, but strongly positively correlated with size of infarct (47). 


\section{Other miRNAs in AMI}

Olivier et al. investigated diagnostic potential of circulating miRNAs in NSTEMI geriatric patients. The authors reported that not only miRNA-499-5p, but also miRNA-21 levels were elevated in NSTEMI versus acute decompensated heart failure without AMI. MiRNA-21 is mostly upregulated in cardiac diseases and its contribution to myocardial disease has been shown via an effect on cardiac fibrosis $(51,52)$. MiRNA-21 upregulated levels were selectively found in fibroblasts of the failing heart as a result of augmented ERK-MAP kinase signaling activity through inhibition of sprout homologue 1 (Spry1) (51). Of note, experimental in vivo silencing of miRNA-21 resulted in antifibrotic and antihypertrophic effect (51).

In another study by Long et. al, the significant change of circulating endothelium-enriched miRNA-126 in a time dependent manner has been found in AMI patients (53). Interestingly, contrary to the previously reported studies, in this study miRNA-126 were downregulated $70 \%, 48 \%, 64 \%, 90 \%, 58 \%, 82 \%$ and $93 \%$ at 4h, 84h, 12h, 24h, 48h, 72h and one week after AMI symptoms onset in comparison to the healthy controls. However, the ROC curves analysis showed moderate ability of miRNA-126 to distinguish between AMI patients and healthy controls (AUC value for different time points varied between 0.83 and 0.88 ) (53).

$\mathrm{Li}$ et al. investigated the altered profile of serum miRNAs in 117 AMI, 182 angina pectoris and 100 gender- and age-matched patients in order to identify miRNA profile useful for the diagnosis of AMI. After initial screening and validation they identified a profile of six serum miRNAs (miRNA-1, miRNA-134, miRNA-186, miRNA-208, miRNA-223 and miRNA-499) as potential AMI biomarkers (35). The overall AUC value for the diagnosis of AMI of signature consisting of six identified miRNAs $\left(\mathrm{AUC}_{\text {miRNAs }}=0.83\right)$ was higher than the use of each of the single miRNAs, and higher than the AUC of $\mathrm{cTnT}\left(\mathrm{AUC}_{\mathrm{cTnT}}=0.77\right)$ and CK-MB $\left(\mathrm{AUC}_{\mathrm{CK}-\mathrm{MB}}=0.71\right)$ when comparing $\mathrm{AMI}$ and unstable angina patients (35). Similar results regarding to miRNAs signature in the course of AMI were presented by Meder at al. They have identified $121 \mathrm{miR}$ NAs in the whole blood samples of patient with AMI which were dysregulated when compared with controls (54). Among these, miRNA-1291 and miRNA-663b characterized by the highest sensitivity and specificity for the discrimination of AMI patients from controls (specificity and sensitivity for miRNA-1291: $85 \%$ and $85 \%$; miRNA-663b: $95 \%$ and $90 \%$ ). The authors have also found with the use of a novel self-learning pattern recognition algorithm an unique signature of 20 miRNAs which predicted AMI with even better power than each of single miRNAs alone (specificity $96 \%$, sensitivity $90 \%$, and accuracy $93 \%$ ) (54). The same authors in another study performed a whole-genome miRNA kinetic study and performed serial miRNAs expression measurements to assess the kinetics of the time-dependent sensitivity of previously reported novel miRNA biomarkers (55). The authors found a signature of seven miRNAs (miRNa-636, miRNA-7-1*, miRNA -380*, miRNA-1254, miRNA-455-3p, miRNA-566, and miRNA-1291) to be dysregulated in very early phase of AMI, and five of them appeared to be a part of the previously discovered 20-miRNAs signature in AMI (55). Surprisingly, miRNA-1, miRNA-133, miRNA-208, and miRNA-499 were not found to be among 20 of the most dysregulated miRNAs detected in the presented study. Of note, this study was based on the whole blood analysis, what may have substantially influenced discovered miRNA expression pattern and thereby presented results cannot be directly compared with others findings obtained from the studies where serum or plasma levels of miRNAs were analyzed.

Recently, miRNA-19a has been identified as another novel potential biomarker for AMI based on a study of 156 AMI patients and 145 control subjects. The authors reported circulating miRNA-19a levels approximately 122 -fold higher in the AMI group compared with controls. They have also concluded after ROC curves analysis that miRNA-19a is a more accurate marker for AMI $\left(\mathrm{AUC}_{\text {miRNA-19a }}=0.997\right)$ than other widely used biomarkers, such as $\mathrm{CK}\left(\mathrm{AUC}_{\mathrm{CK}}=0.81\right)$, CK-MB $\left(\mathrm{AUC}_{\mathrm{CK}-\mathrm{MB}}=0.511\right)$ and hs-cTnI $\left(\mathrm{AUC}_{\mathrm{hs}-\mathrm{cTnI}}=\right.$ $0.717)(56)$.

\section{POTENTIAL OF miRNAs IN CARDIOVASCULAR THERAPY}

After documenting the essential role of miRNA at the cellular level and its contribution to cardiovascular development, several researches started focusing on the potential therapeutic role of miRNA. The most important difficulty in the therapeutic use of miRNAs is connected with the fact that each miRNA can bind multiple mRNA targets, affecting expression of numerous genes and proteins. From the other hand, each mRNA has multiple miRNAs that can bind it, what results in an extremely complex and unpredictable network of reciprocal molecular relationships. Actual potential treatment options with the use of miRNAs imply the idea of influencing the levels of miRNAs in particular diseases. The therapeutic goal can be achieved by both suppression of miRNAs (with the use of antagomirs) as well as raising miRNAs levels or substituting them by exogenous copies (with the use of miRNA mimics) - depending on the disease pathophysiology. 


\section{Antagomirs}

In situation when specific miRNA has a well-documented role in disease pathophysiology and its overexpression is considered deleterious, therapeutic silencing can be achieved through using antisense oligonucleotides (antagomirs) - single-stranded synthetic oligonucleotides. MiRNAs expression can be affected by antagomirs at different levels of theirs biogenesis: [1] inhibition of the pre-miRNA export to the cytoplasm, [2] blocking the transformation of pre-miRNA into mature miRNA and its entry into the RISC or [3] through complementary binding to the specific mature miRNA within the RISC complex and acting as competitive inhibitor (57). This approach is similar to previously used traditional concept of antisense targeting of mRNAs, however, the potential number of targeting sites for miRNA is extremely limited in contrast to the mRNA (57).

\section{miRNAs mimics}

Other therapeutic approach are miRNA mimics synthetic RNA duplex with one strand identical to the target miRNA. When a some specific miRNA is downregulated during disease or exerts a notable beneficial effect, it can be enhanced via miRNA mimics. However, special caution should be exercise in its use, because the complimentary strand may act as a separate miRNA with incalculable effect (58). MiRNA mimics are particularly interesting, because this type of approach is quite analogous to the small interfering RNA (siRNA) molecules, which have been commonly used in gen silencing (57).

\section{Exosomal miRNA}

Exosomes are 40-100 nm vesicles which are extracellular organelles important in communication between cells. They are released from many different cells into the extracellular space (11). MiRNAs are incorporated either into exosomes or HDL and therefore they are quite stable (59). The another major challenge of using exogenous miRNAs as therapeutics is their relatively quick degradation by the ribonucleases present in human plasma (19). Therefore, exosomes seem to be ideal candidates as miRNAs carriers, because of their stability, no immunogenicity and miRNAs protective character $(13,60)$. Exosomes containing miRNAs were proposed as novel stable therapeutic carriers, which can be delivered to specific cell, and there can be functionally modifying different target genes expressions (13). Moreover, studies have proven that different cells may differ in their capacity of exosomes incorporation, and the surface cell receptor specificity has been indicated as a crucial factor for their internalization (61).

\section{Current status of miRNAs therapeutics}

To date, the only a few miRNA-targeted therapies entered clinical trials.

Miravirsen (SPC3649) is the first miRNA-based drug, that is being investigated for a treatment of chronic hepatitis $\mathrm{C}$ virus (HCV) infection by miRNA-122 inhibition (antagomir). Miravirsen acts by sequestering and therefore inhibition of miRNA-122 which appeared to be crucial for the propagation and stability of HCV RNA (62). In 2013 the promising results in phase 2a trial of miravirsen showed that 5 weekly subcutaneous injections of miravirsen resulted in a prolonged dose-dependent reduction in HCV-RNA levels without evidence of viral resistance (62). Recently, another miRNA-based therapeutic-MRX34 (MirnaTherepeutics) entered Phase I clinical trial for treatment advanced or metastatic liver cancer. MRX 34 is an innovative liposomal nanoparticle formulation loaded with the miRNA-34a mimic as the active pharmacological ingredient. In preclinical studies MRX34 reduced tumor growth and enhanced survival (63).

Several other miRNA-oriented therapeutic approaches for cardiovascular diseases are also already in preclinical trial phase: miRNA-21, miRNA-195, miRNA-1 and miRNA-133 in cardiac hypertrophy and remodeling, miRNA-29 in cardiac fibrosis, miRNA-133 in arrhythmias, miRNA-126 in angiogenesis, miRNA-208 in heart failure and cardiometabolic disease, miRNA-33 in atherosclerosis, miRNA-15 family in postinfarction left ventricular remodeling and cardiac regeneration, miRNA-145 in pulmonary hypertension, and miRNA-92a as angiogenetic agent $(57,64)$. Given the extensive bioeffects expressed by miRNAs, the hopes and expectations for their successful therapeutic use are significant.

\section{CONCLUSIONS}

Accumulating evidence indicates that circulating miRNAs can be quantified to provide useful, stable biomarkers for AMI. Despite the fact that results of presented studies are not fully consistent, cardiac-specific miRNAs (miRNA-208, miRNA-499, miRNA-133 and miRNA-1) seem to be the most promising biomarker candidates which might improve the diagnostics of AMI, especially in the earliest phase. The attractiveness of miRNAs as biomarkers may lead in early future to development of promising miRNAs-based diagnostic approach improving early diagnosis and risk stratification in patients with AMI suspicion. Furthermore, there is growing evidence that several miRNAs are attractive therapeutic candidates to reduce negative cardiac remodeling by improving neovascularization and limiting tissue injury, and thereby improving post-infarction healing.Future miRNA-based therapeutics may offer an 
important progress in numerous clinical indications currently tested in early phase clinical trials and thus an immense step towards personalized medicine.

\section{Acknowledgments}

This work was supported by Polish Ministry of Science and Higher Education as "Diamond Grant" Program, research project: DIA012942.
Abbreviations
AMI - acute myocardial infarction
CABG - coronary artery bypass grafting

CK - creatine kinase

CK-MB - MB isoenzyme of creatine kinase

cTn - cardiac troponin

cTnI - cardiac troponin I

cTnT - cardiac troponin T

hs-cTn - high-sensitivity caradic troponin (T or I)

mRNAs - messenger ribonucleic acids

miRNAs - micro ribonucleic acids

STEMI - ST elevation myocardial infarction

NSTEMI - non-ST elevation myocardial infarction

$\mathbf{9 5} \% \mathbf{C I}-95 \%$ confidence interval

\title{
Sažetak
}

\section{MicroRNA KAO BIOMARKERI AKUTNOG INFARKTA MIOKARDA — MALI MOLEKULI SA VELIKIM POTENCIJALOM}

\author{
Miøkowiec Dawid, ${ }^{1}$ Kasprzak Jaroslaw D. \\ ${ }^{1}$ Department of Cardiology, Medical University of Lodz, Poland
}

MikroRNA (miRNAs) predstavljaju klasu malih, 17-25 nukleotida dugih, nekodirajućih RNA kiselina. One deluju kao regulatori genske ekspresije, bilo blokiranjem translacije ili indukujući degradaciju miRNA sekvence-specifičnom hibridizacijom. Nekoliko miRNA su predložene kao potencijalni biomarkeri specifični za kardiovaskularne bolesti. Dijagnostička vrednost procene nivoa cirkulišućih miRNA je ispitivana $u$ brojnim studijama, uglavnom u vezi sa akutnim infark-

\section{REFERENCES}

1. Lander ES, Linton LM, Birren B, et al. Initial sequencing and analysis of the human genome. Nature. 2001; 409(6822): 860-921.

2. Wilusz JE, Sunwoo H, Spector DL. Long noncoding RNAs: functional surprises from the RNA world. Genes Dev. 2009;23(13):1494-504.

3. Bartel DP. MicroRNAs: genomics, biogenesis, mechanism, and function. Cell. 2004; 116(2): 281-97.

4. Jonas S, Izaurralde E. Towards a molecular understanding of microRNA-mediated gene silencing. Nat Rev Genet. 2015; 16(7): 421-33

5. Du T, Zamore PD. microPrimer: the biogenesis and function of microRNA. Dev Camb Engl. 2005; 132(21): 4645-52.

6. Kozomara A, Griffiths-Jones S. miRBase: integrating microRNA annotation and deep-sequencing data. Nucleic Acids Res. 2011;39 (Database issue): D152-7.

7. Guo H, Ingolia NT, Weissman JS, Bartel DP. Mammalian microRNAs predominantly act to decrease target mRNA levels. Nature. 2010; 466(7308): 835-40.

8. Baek D, Villén J, Shin C, Camargo FD, Gygi SP, Bartel DP. The impact of microRNAs on protein output. Nature. 2008; 455(7209): 64-71. tom miokarda. Obećavajući inicijalni rezultati prekliničkih studija ukazuju na potencijal terapije zasnovane na miRNA. U našem radu se fokusiramo na aktuelna saznanja koja pokazuju ulogu miRNA u akutnom infarktu miokarda, Đpard fs20 naglašavajući dijagnostičku korist miRNA kao obećavajućih novih biomarkera za AIM i njihov terapeutski potencijal.

Ključne reči: microRNA, infarkt miokarda, bolest koronarnih arterija, miokard, regulacija genske ekspresije.

9. Selbach M, Schwanhäusser B, Thierfelder N, Fang Z, Khanin R, Rajewsky N. Widespread changes in protein synthesis induced by microRNAs. Nature. 2008; 455(7209): 58-63.

10. Liang Y, Ridzon D, Wong L, Chen C. Characterization of microRNA expression profiles in normal human tissues. BMC Genomics. 2007; 8:166.

11. Zhang J, Li S, Li L, et al. Exosome and Exosomal MicroRNA: Trafficking, Sorting, and Function. Genomics Proteomics Bioinformatics. 2015; 13(1): 17-24.

12. Miœkowiec D, Kasprzak JD. MicroRNAs as new biomarkers of the cardiovascular diseases - current communications review. Pol Przegl Kardiol. 2013; 15(1): 69-72.

13. Valadi H, Ekström K, Bossios A, Sjöstrand M, Lee JJ, Lötvall JO. Exosome-mediated transfer of mRNAs and microRNAs is a novel mechanism of genetic exchange between cells. Nat Cell Biol. 2007; 9(6): 654-9.

14. Lee Y, Ahn C, Han J, et al. The nuclear RNase III Drosha initiates microRNA processing. Nature. 2003; 425(6956): 415-9.

15. Ha M, Kim VN. Regulation of microRNA biogenesis. Nat Rev Mol Cell Biol. 2014; 15(8): 509-24.

16. Creemers EE, Tijsen AJ, Pinto YM. Circulating MicroRNAs Novel Biomarkers and Extracellular Communicators in Cardiovascular Disease? Circ Res. 2012; 110(3): 483-95. 
17. Weber JA, Baxter DH, Zhang S, et al. The microRNA spectrum in 12 body fluids. Clin Chem. 2010; 56(11): 1733-41.

18. D'Alessandra Y, Devanna P, Limana F, et al. Circulating microRNAs are new and sensitive biomarkers of myocardial infarction. Eur Heart J. 2010; 31(22): 2765-73.

19. Mitchell PS, Parkin RK, Kroh EM, et al. Circulating microRNAs as stable blood-based markers for cancer detection. Proc Natl AcadSci U S A. 2008; 105(30): 10513-8.

20. Turchinovich A, Weiz L, Langheinz A, Burwinkel B. Characterization of extracellular circulating microRNA. Nucleic Acids Res. 2011; 39(16): 7223-33.

21. Lee LW, Zhang S, Etheridge A, et al. Complexity of the microRNA repertoire revealed by next-generation sequencing. RNA. 2010; 16(11): 2170-80.

22. Wang Y, Zheng D, Tan Q, Wang MX, Gu L-Q. Nanopore-based detection of circulating microRNAs in lung cancer patients. Nat Nanotechnol. 2011; 6(10): 668-74.

23. Zhao Y, Zhou L, Tang Z. Cleavage-based signal amplification of RNA. Nat Commun. 2013; 4: 1493.

24. Fichtlscherer S, De Rosa S, Fox H, et al. Circulating microRNAs in patients with coronary artery disease. Circ Res. 2010; 107(5): 677-84.

25. Klimczak D, Paczek L, Jazdzewski K, Kuch M. MicroRNAs: powerful regulators and potential diagnostic tools in cardiovascular disease. Kardiol Pol. 2015; 73(1): 1-6.

26. Sayed ASM, Xia K, Yang T-L, Peng J. Circulating microRNAs: A Potential Role in Diagnosis and Prognosis of Acute Myocardial Infarction. Dis Markers. 2013; 35(5): 561-6.

27. Van Rooij E, Quiat D, Johnson BA, et al. A Family of microRNAs Encoded by Myosin Genes Governs Myosin Expression and Muscle Performance. Dev Cell. 2009; 17(5): $662-73$.

28. Economou EK, Oikonomou E, Siasos G, et al. The role of microRNAs in coronary artery disease: From pathophysiology to diagnosis and treatment. Atherosclerosis. 2015; 241(2): 624-33.

29. Adachi T, Nakanishi M, Otsuka Y, et al. Plasma microRNA 499 as a biomarker of acute myocardial infarction. Clin Chem. 2010; 56(7): 1183-5.

30. Wang G-K, Zhu J-Q, Zhang J-T, et al. Circulating microRNA: a novel potential biomarker for early diagnosis of acute myocardial infarction in humans. EurHeart J. 2010; 31(6): 659-66.

31. Bialek SG, Górko D, Zajkowska A, et al. Release kinetics of circulating miRNA-208a in early phase of myocardial infarction. Kardiol Pol ŠInternet ${ }^{1} .2015$ Šcited 2015 Jul 10¹; Available from: http://ojs.kardiologiapolska.pl/kp/article/view/KP. a2015.0067

32. Zile MR, Mehurg SM, Arroyo JE, Stroud RE, DeSantis SM, Spinale FG. Relationship between the temporal profile of plasma microRNA and left ventricular remodeling in patients after myocardial infarction. Circ Cardiovasc Genet. 2011; 4(6): 614-9.

33. Corsten MF, Dennert R, Jochems S, et al. Circulating MicroRNA-208b and MicroRNA-499 reflect myocardial damage in cardiovascular disease. Circ Cardiovasc Genet. 2010; 3(6): 499-506.

34. Devaux Y, Vausort M, Goretti E, et al. Use of circulating microRNAs to diagnose acute myocardial infarction. Clin Chem. 2012; 58(3): 559-67.
35. Li C, Fang Z, Jiang T, et al. Serum microRNAs profile from genome-wide serves as a fingerprint for diagnosis of acute myocardial infarction and angina pectoris. BMC Med Genomics. 2013; 6:16.

36. Gidlöf O, Smith JG, Miyazu K, et al. Circulating cardio-enriched microRNAs are associated with long-term prognosis following myocardial infarction. BMC CardiovascDisord. 2013; 13(1): 12 .

37. Devaux Y, Mueller M, Haaf P, et al. Diagnostic and prognostic value of circulating microRNAs in patients with acute chest pain. J Intern Med. 2015; 277(2): 260-71.

38. Endo K, Weng H, Naito Y, et al. Classification of various muscular tissues using miRNA profiling. Biomed Res Tokyo Jpn. 2013; 34(6): 289-99.

39. Widera C, Gupta SK, Lorenzen JM, et al. Diagnostic and prognostic impact of six circulating microRNAs in acute coronary syndrome. J Mol Cell Cardiol. 2011; 51(5): 872-5.

40. Cheng C, Wang Q, You W, Chen M, Xia J. MiRNAs as biomarkers of myocardial infarction: a meta-analysis. PloS One. 2014; 9(2): e88566.

41. Shieh JTC, Huang Y, Gilmore J, Srivastava D. Elevated miR-499 Levels Blunt the Cardiac Stress Response. PLoS ONE. 2011; 6(5): e19481.

42. Zhang L, Chen X, Su T, et al. Circulating miR-499 are novel and sensitive biomarker of acute myocardial infarction. J Thorac Dis. 2015; 7(3): 303-8.

43. Olivieri F, Antonicelli R, Lorenzi M, et al. Diagnostic potential of circulating miR-499-5p in elderly patients with acute non ST-elevation myocardial infarction. Int J Cardiol. 2013; 167(2): 531-6.

44. Yao Y, Du J, Cao X, et al. Plasma Levels of MicroRNA-499 Provide an Early Indication of Perioperative Myocardial Infarction in Coronary Artery Bypass Graft Patients. PLoS ONE [Internet]. 2014 Aug 11 [cited 2015 Jul 13]; 9(8). Available from: http://www.ncbi.nlm.nih.gov/pmc/articles/PMC4128681/

45. Han M, Toli J, Abdellatif M. MicroRNAs in the cardiovascular system.CurrOpinCardiol. 2011; 26(3): 181-9.

46. Liu N, Bezprozvannaya S, Williams AH, et al. microRNA-133a regulates cardiomyocyte proliferation and suppresses smooth muscle gene expression in the heart. Genes Dev. 2008; 22(23): 3242-54.

47. Ai J, Zhang R, Li Y, et al. Circulating microRNA-1 as a potential novel biomarker for acute myocardial infarction. BiochemBiophys Res Commun. 2010; 391(1): 73-7.

48. Mishima Y, Stahlhut C, Giraldez AJ. miR-1-2 gets to the heart of the matter. Cell. 2007; 129(2): 247-9.

49. Zhao Y, Ransom JF, Li A, et al. Dysregulation of Cardiogenesis, Cardiac Conduction, and Cell Cycle in Mice Lacking miRNA-1-2. Cell. 2007; 129(2): 303-17.

50. Yang B, Lin H, Xiao J, et al. The muscle-specific microRNA miR-1 regulates cardiac arrhythmogenic potential by targeting GJA1 and KCNJ2. Nat Med. 2007; 13(4): 486-91.

51. Thum T, Gross C, Fiedler J, et al. MicroRNA-21 contributes to myocardial disease by stimulating MAP kinase signalling in fibroblasts. Nature. 2008; 456(7224): 980-4.

52. Rooij E van, Sutherland LB, Liu N, et al. A signature pattern of stress-responsive microRNAs that can evoke cardiac hypertrophy and heart failure. Proc Natl Acad Sci. 2006; 103(48): 18255-60.

53. Long G, Wang F, Duan Q, et al. Human Circulating MicroRNA-1 and MicroRNA-126 as Potential Novel Indicators 
for Acute Myocardial Infarction. Int J Biol Sci. 2012; 8(6): $811-8$.

54. Meder B, Keller A, Vogel B, et al. MicroRNA signatures in total peripheral blood as novel biomarkers for acute myocardial infarction. Basic Res Cardiol. 2011; 106(1): 13-23.

55. Vogel B, Keller A, Frese KS, et al. Refining diagnostic microRNA signatures by whole-miRNome kinetic analysis in acute myocardial infarction. Clin Chem. 2013; 59(2): 410-8.

56. Zhong J, He Y, Chen W, Shui X, Chen C, Lei W. Circulating microRNA-19a as a Potential Novel Biomarker for Diagnosis of Acute Myocardial Infarction. Int J Mol Sci. 2014; 15(11): 20355-64.

57. Van Rooij E, Marshall WS, Olson EN. Toward microRNA-based therapeutics for heart disease: the sense in antisense. Circ Res. 2008; 103(9): 919-28.

58. Van Rooij E, Sutherland LB, Thatcher JE, et al. Dysregulation of microRNAs after myocardial infarction reveals a role of miR-29 in cardiac fibrosis. Proc Natl AcadSci U S A. 2008; 105(35): 13027-32.

\section{Correspondence to /Autor za korespondenciju}

Dawid Miskowiec, MD

Department of Cardiology, Medical University of Lodz, Poland

Kniaziewicza Street 1/5, 91-347, Lodz, Poland

Telephone: +48 4225162 16, Fax: +48 426539909

e-mail: dawid.miskowiec@gmail.com
59. Sahoo S, Losordo DW. Exosomes and cardiac repair after myocardial infarction. Circ Res. 2014; 114(2): 333-44.

60. Alvarez-Erviti L, Seow Y, Yin H, Betts C, Lakhal S, Wood MJA. Delivery of siRNA to the mouse brain by systemic injection of targeted exosomes. Nat Biotechnol. 2011; 29(4): $341-5$.

61. Christianson HC, Svensson KJ, van Kuppevelt TH, Li J-P, Belting M. Cancer cell exosomes depend on cell-surface heparan sulfate proteoglycans for their internalization and functional activity. Proc Natl AcadSci U S A. 2013; 110(43): 17380-5.

62. Janssen HLA, Reesink HW, Lawitz EJ, et al. Treatment of HCV Infection by Targeting MicroRNA. N Engl J Med. 2013; 368(18): 1685-94.

63. Bader AG. miR-34 - a microRNA replacement therapy is headed to the clinic. Front Genet. 2012; 3:120.

64. Van Rooij E, Olson EN. MicroRNA therapeutics for cardiovascular disease: opportunities and obstacles. Nat RevDrugDiscov. 2012; 11(11): 860-72. 